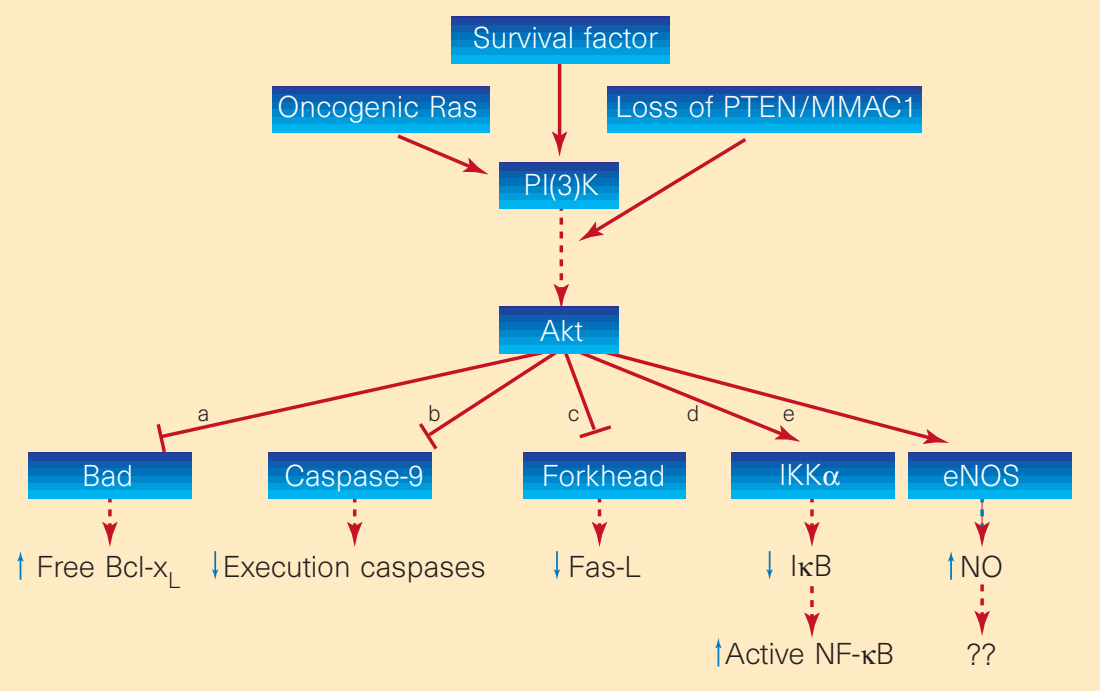

Figure 2 Potential mechanisms by which the Akt serine kinase can regulate cell survival.

Phosphoinositide-3-OH kinase (PI(3)K) signalling can be activated by extracellular survival factors, by activating mutations in the Ras oncogene, or by a deletion/inactivating mutation of PTEN/MMAC1 (phosphatase and tensin homologue/mutated in multiple advanced cancers), a phospholipid phosphatase. This leads to activation of Akt. Phosphorylation by activated Akt can then: a, sequester the pro-apoptotic protein Bad, leading to increased free (anti-apoptotic) Bcl- $\mathrm{x}_{\mathrm{L}}$; $\mathrm{b}$, inhibit the activity of the cell-death protease caspase-9, diminishing the activation of target execution caspases; $c$, prevent nuclear localization of Forkhead transcription factors, reducing the transcription of Fas ligand (Fas-L); d, promote the degradation of I $K B$ and increase the activity of NF$\kappa \mathrm{B}$, leading to increased synthesis of anti-apoptotic proteins; or e, increase the activity of endothelial nitric oxide synthase (eNOS), leading to increased production of nitric oxide (NO).

direct targets of Akt. Genetic studies in the nematode worm Caenorhabditis elegans had previously shown ${ }^{11}$ that a $\mathrm{PI}(3) \mathrm{K} / \mathrm{Akt}$ pathway suppresses the function of DAF-16, a member of the Forkhead family. In the worm, this pathway regulates aspects of metabolism and longevity. Phosphorylation of mammalian members of the Forkhead family by Akt results in their being retained in the cytoplasm, preventing them from affecting transcription. In some cells this mechanism may regulate apoptosis by inhibiting the transcription of the gene that encodes the death-activating Fas ligand ${ }^{9}$ (Fig. 2). No doubt, though, other targets will also be involved.

Also this year, two groups ${ }^{12,13}$ have shown that Akt can influence the production of nitric oxide. It does so by directly phosphorylating nitric oxide synthase in the endothelium. Although the nitric oxide produced by this pathway is mainly involved in modulating vascular tone and the formation of new blood vessels, there is evidence ${ }^{14}$ linking it to pathways that regulate apoptosis. Endothelial cell-survival pathways are known to involve Akt, and it remains to be seen whether nitric oxide plays a part in this process.

The research on Akt signalling shows that a single regulatory molecule can exert its anti-apoptotic effects in a variety of ways. One implication of these results is that armchair-based generalizations on how apoptosis is controlled are no longer tenable. We

should not be surprised when our own favourite cell line behaves differently to someone else's — such cells will probably have developed individual molecular quirks that maintain their immortality. A challenge now is to make sense of the networks that control apoptosis, and the focus may need to shift away from cell lines to primary tissues. To find out what molecules are involved in controlling apoptosis in the physiological or disease process that you are interested in, you will have to head for the bench. This means that the huge research effort into the mechanics of cell death is likely to continue for some time.

Asim Khwaja is in the Department of Haematology, University College London Medical School,

98 Chenies Mews, London WC1E 6HX, UK. e-mail:a.khwaja@ucl.ac.uk

1. Downward, J. Curr. Opin. Cell Biol. 10, 262-267 (1998).

2. Ozes, O. N. et al. Nature 401, 82-85 (1999).

3. Romashkova, J. A. \& Makarov, S. S. Nature 401, 86-90 (1999).

4. Maehama, T. \& Dixon, J. E. Trends Cell Biol. 9, 125-128 (1999).

5. Datta, S. R. et al. Cell 91, 231-241 (1997).

6. Cardone, M. H. et al. Science 282, 1318-1321 (1998).

7. Kane, L. P., Shapiro, V. S., Stokoe, D. \& Weiss, A. Curr. Biol. 9, 601-604 (1999).

8. Wang, C. Y., Mayo, M. W., Korneluk, R. G., Goeddel, D. V. \& Baldwin, A. S. Jr Science 281, 1680-1683 (1998).

9. Brunet, A. et al. Cell 96, 857-868 (1999).

10. Kops, G. J. et al. Nature 398, 630-634 (1999).

11. Paradis, S. \& Ruvkun, G. Genes Dev. 12, 2488-2498 (1998).

12. Dimmeler, S. et al. Nature 399, 601-605 (1999).

13. Fulton, D. et al. Nature 399, 597-601 (1999).

14. Dimmeler, S., Haendeler, J., Nehls, M. \& Zeiher, A. M. J. Exp. Med. 185, 601-607 (1997).
Daedalus

\section{Slip through the water}

Daedalus once invented a red-hot boat. The water could never touch its hull, which was insulated by a thin layer of steam. So it had extremely low skinfriction, and no trouble with fouling weeds or barnacles either. But its fuel costs were high, and its insulation problems severe.

He now returns to the field with a converse scheme. He wants to coat a ship with ice. He argues that ice must have the lowest skin-friction against water of any solid. Furthermore, in its flow past the ice, the water would tend to melt away preferentially those features that obstructed the stream lines. The hull would shape itself into the perfect streamline form for minimum drag. But again, the idea suffers from heat-transfer problems. This time, Daedalus has a way out. He wants to coat his ship with foamed ice.

Foamed ice, like foamed polystyrene, would be an excellent thermal insulator. DREADCO engineers are now exploring ways of making it. The simplest idea is just to make the surface of the cooled hull porous, and pump air out of the holes as the water freezes onto it. Another is to saturate the surrounding water with a gas such as carbon dioxide, which is expelled by water as it freezes. It might even be possible to generate the gas electrolytically, using electrodes integral with the hull. But whichever way proves best, the ship will build up its primary ice-coating in port, and only have to maintain it against melting at sea. A good refrigerator can pump heat at several times its own powerdrain. Daedalus estimates that a few tens of kilowatts of refrigeration could maintain a foamed ice-sheet over the wetted surface of even a sizeable freighter. Its slippery coating, proof against fouling organisms, should save many hundreds of kilowatts of propulsive power. And in a maritime accident, the ship could make instant rafts and lifeboats of foamed ice, to support the crew until help arrived.

Foamed ice should have many other uses too. The DREADCO team hopes to develop a generator to make it in quantity on land. A given volume of water would make a much larger volume of foamed ice. Unlike snow, it would have a closed-cell structure, impermeable and very rigid; and its low thermal conductivity would limit its rate of melting. It would be ideal for temporary structures such as crash barriers, fire breaks, scaffolding, skiramps and foamed igloos for emergency shelter. David Jones 